The Geneva Papers on Risk and Insurance, 23 (No. 89, October 1998), 500-505

\title{
At the Turn of the Century: Reflections on the Insurance Industry in Society
}

\author{
by Björn Wolrath*
}

We who live today are fortunate: we see, in spite of political turbulence as new boundaries are laid and unemployment plagued fundamentally prosperous nations, the beginning of a new and promising era where individual entreprises will have an ever greater role to play. Old institutions are playing out the last days of their role, and this affects almost every aspect of the social structure we are accustomed to: educational systems, employer - employee relationships, and the political debate which is supposed to resolve perceived problems.

This century has witnessed the definitive victory of the capitalist system, a concommittent and a dramatic rise in the standard of living in the majority of the nations of the world. The opening of borders sealed by decisions taken by a handful of politicians a little over 50 years ago provides opportunities and challenges on many levels. To support the development of a stable financial system in the former Eastern Block and to contribute to the growth of a financial services market able to correctly respond to the needs of the public is a clear task for the insurance industry in Western Europe.

The entry into the international area of this highly educated pool of labor and growing insurance expertise will initially be characterized by a combination of partnership and competition in the markets of the former Soviet block. A decade or so into the next century, eastern European players may well be active in the western arena as well.

Literacy has become the right of humanity rather than the privilige of a few. However, the forms it takes are not those we learned in our childhood. In recent years, the development of information technology has opened the doors of education even to those

\footnotetext{
* Chairman, Swedish Insurance Federation.
} 
unable to attend classes in traditional institutions of learning. Distance learning and open universities are already having a great democratizing effect.

\section{New role for insurance}

At the same time we in Europe have seen the gradual but accelerating erosion of state-supported systems for education, health and medical care, social security and pensions. Some of these needs can be met through the private sector and indeed represent significant and well-documented market opportunities for the insurance industry.

However, the picture is more complicated. We see the emergence of a permanent underclass in the great cities of Europe, people of differing ethnic backgrounds who do not necessarily share the values of the society they have moved to, because they have never been in real contact with them.

Persistent unemployment and tax regimes that do not encourage establishment of new, small companies, darken the picture further. Children from affluent families whose parents are too engaged in their work represent yet another risk group. History has shown how easily violent messages can play upon the feelings of those who are materially or emotionally disadvantaged. The estrangement of a significant number of people from productive life is a dangerous trend which can jeopardize the achievements of past and present generations. For society at large, every day that passes without using the potential of the population represents an immediate moral and subsequently even a financial loss.

\section{Ideas for life}

For institutions such as insurance companies, the situation presents challenges that cannot be ignored. During my years as CEO of Skandia, we developed a number of programs that might be categorized as societal risk mangement. Over a period of over ten years we developed the structures for what we called Ideas for Life. The point of departure was the perception of cracks between the various state and municipal institutions in Sweden. Children who at an early stage showed signs of violent behavior were not always given the guidance to correct their attitude. Only when they reached the stage of juvenile delinquency, when they made their first visit to the police station, was their situation identified. By then it was too late.

For every state or municipal, body working according to its well-founded and sincere principles, there are hundreds of people who have privately or in groups, used their own ingenuity to resolve the same problems. By letting these people come forward and giving financial support to these volunteer organizations through a specially created foundation, Skandia has made it possible for parents to patrol the streets, for skin-heads and immigrants to meet peacefully at facilities in an old cold storage house to play music, practice wall climbing and engage in education and other activities in an environment they can identify with.

Skandia has developed a still-growing cooporation with the police, with the schools, with the day care centers, with health care experts. Courses have been held for 70,000 people who encounter children and young people in the course of their profession. Training has been provided in recognizing the symptoms of future problems or in 
identifying tragedies that have already occurred, such as the abuse of children. Skandia employees have acted as ambassadors and as volunteers. Funneling the limited resources available in various institutions has leveraged the aid that can be mustered in society as a whole.

What is idealism on one hand, has a clear economic value on the other. All large cities struggle with the destruction caused by grafiti, vandalism, and arson. Like any other kind of risk management, societal risk management represents an initial investment which, if not made, can lead to economic losses whose scope it is difficult to assess.

\section{Ideas for enterprising}

A subsequent Skandia project, Ideas for Enterprising, addresses the needs of small and medium-sized companies. The project gives added value to the client companies participating by opening an Internet marketplace and by assisting in finding the necessary risk capital new entreprises require. The project involves the use of Skandia's contacts in the Far East as a support for small companies wishing to export there. Here too, the thrust of the project is to encourage private initiative. A thriving small business culture can be directly translated into insurance business terms. Small companies grow. They create jobs. They create new insurable risks and new target groups for group pension schemes.

Both of these projects have been implemented in Sweden. They are, however, quite in the spirit of the Geneva Asssociation which, for 25 years, has constantly been exploring the limits of insurability and identifying the economic role of insurance companies in society. The stringent international research conducted by the Geneva Association and the analyses presented at its meetings provide material needed to convince both private organizations and the political sphere of the necessity of reforms.

\section{Pension reform imminent}

The Geneva Association has done considerable research on the future of work and retirement. In this connection the radical reshaping of the Swedish pension system can serve as an example. The Swedish pension system is at present the only one making the change from a pay as you go to a funded reserve system in the near future. The reformed system will be introduced gradually on a sliding scale. Those who are now 50 , for instance, will receive a pension half based on the old system and half on the new one. The new pension will be based on lifetime income, including income from employment, and social security benfits. 18.5 percent of the individual's lifetime earnings is to be paid into the pension system; of this, 2.5 percentage points will earn interest in a premium reserve account. The person insured can choose an investment manager from the private sector or let the state continue to administer the funds. Contributions to the pay-as-you-go scheme as well as later payouts will be related to the economic growth of the country.

Skandia has organized several conferences on the necessity of a pension reform and suggested the modality it should take. Most recently, in 1997, Martin Feldstein of the National Bureau of Economic Research in the United States, presented his thoughts on the positive effects of a reformed, funded pension system. Swedish researchers who have applied his theory have come to striking conclusions: they found that the Swedish GNP would be 8-17 percent higher if the pension system were based on funded savings. That 
argumentation takes into consideration the elimination of present unnecessary taxes in the labor market that amount to an estimated 3.2-8.2 percent of GNP and the fact that free investment of the funded reserves conducted by competing fund managers would give individuals a higher yield on savings between 4.9-9.2 percent of GNP.

\section{Competence insurance}

It is by now common place to observe that we live in a world of continuous change. The amount of new knowledge doubles every four to five years. This means that traditional educational patterns are insufficient to assure employment during an entire working life. The Swedish electronics company Ericsson estimates that 60 percent of its entire production has been developed during the past two years. At Skandia, in 1996 it was observed that half of the revenue came from products and services developed in the past ten years. Clearly such an evolution has an impact on the composition of the work force. OECD studies have shown that each year 10 percent of the jobs in the industrialized countries disappear. At the same time, 10 percent new jobs requiring a high degree of qualification are created, but the supply of people with the right training is only 3 percent. Such an education deficit can have serious consequences for a country.

Skandia has launched a proposal for a competence insurance, which would involve matched contributions (about 5 percent of salary) from both the employee and the employer over a period of 6-8 years to finance professionally oriented studies for a period of 6-18 months. Using the administrative expertise developed in an insurance company, the system would permit a continuous alternation of work and education at various stages of life. The scope of the studies would be determined by the employee and employer together and if the employee left the company he would take his share of the savings with him. The proposal has been greeted with enthusiasm by politicians and trade unions. Its implementation is dependent on changes in the tax legislation, which would stimulate such a savings form. The Swedish Prime Minister has recently announced the formation of an inter-ministerial board to study the means of financing added competence in the working population, which means that the private alternative may well come to have an essential role.

The insurance industry today and tomorrow will have an ever larger role to play, as it assumes responsibilities that were previously the province of the state or that were not addressed at all.

\section{Consolidation}

The consolidation process we now see in the insurance industry has its equivalent in the pharmaceutical, accounting and consulting sectors to name a few examples. The rationale is usually economies of scale, the possibility to reduce personnel and thus improved value added ratios as well as to offer a wider gamut of services. At the same time, the advent of the EMU and the transparency that entails, will further reduce traditional insurance to commodity status. Consolidation is often accompanied by the opposite phenomenon, outsourcing of specialist competencies or entire divisions working with investment, IT or claims handling. While this may reduce expenses in the short term, the practice presents new challenges that must be addressed. How is quality of service to 
be controlled? How can valuable information gathered in connection with claims adjustment be channeled back to those packaging products and setting premium rates? In the final analysis, how is the individual company's competitiveness to be maintained over time?

\section{New methods of managing risk}

The cyclical nature of the non-life insurance industry has led to i.a. a consolidation in the reinsurance sector. New financial methods for containing risk exposure ranging from captives to securitization to risk retention groups have altered the size of the traditional non-life insurance playing field. Increasingly, insurance companies are developing feebased alternative solutions which give growth possibilities even in markets where premium growth is stagnating. In this context, it is essential to act without preconceptions. Perhaps the very activity that is in the process of being outsourced by one company is conducted with such professionality that it can be offered as a service to others on a contract basis.

Unbundling of services has many aspects. Seen from the client's perspective, the transparency inherent in EMU practices will reinforce the trend as i.a. commissions and expense margins are specified. Large industrial purchasers of insurance will be able to influence the scope and orientation of their insurance cover and its cost to a previously inconceivable extent. Insurance will be increasingly only one of several methods to control risk. Progressive insurance companies will offer services in addition to capital capacity.

Life and pension assurance is increasingly placed in the savings sector rather than the insurance area and hence has a wide variety of challenges before it. Banks and other financial institutions are known competitors today. However, the fund managers for whom banks and insurance companies act as distribution channels today can in the future develop their own contacts with the public via as yet unknown entrants.

These considerations may be unsettling for today's managing directors. At the same time, they can be sure that they act in a sector whose development is essential to society. The question is how insurance cover will be integrated into the new society we see emerging. It is vital that those active in the market see to it that insurance expertise continues to be the hub of methods adopted for increasingly sophisticated risk control.

\section{Insurability}

Expanding the realm of insurability and finding new areas where insurance expertise can meet the needs of the public and contribute to the creation of wealth in society are critical issues for all those involved in this dynamic industry.

The accumulated experience of the Geneva Association has made significant contributions to these efforts. Developments now at the turn of the century indicate that the Association will have an even greater role to play in the definition of insurance and insurability as well as confirming the social and economic mandate of the players in the industry.

The turbulence now accompanying the current reform of state pension and other welfare structures can be interpreted as a sign of the need for a new order, where the insurance industry will have an even greater role in society, naturally as a provider of 
financial security in the traditional sense but also as an investor in areas of societal significance.

The increase of revenue flowing into the insurance industry as a consequence of the privatisation process is the financial indication of a major shift in roles. As the realm of state activities is reduced, it will be the industry's moral imperative to involve itself to a greater extent in the fabric of society, leveraging its position and greater economic strength, discovering new needs and exercising new mandates. As society changes and the actors in it find their new responsibilities, the forum and authority provided by the Geneva Association will undoubtedly continue to have a important role in identifying the standards of corporate responsibility and the scope of insurability. 